\title{
Um Estudo Sobre Emoções Indexadas e Emoções Sentidas Utilizando Imagens do Flickr
}

\author{
Renata G. Bianchi \\ Departamento de Computação \\ UFSCar \\ São Carlos, SP, Brasil \\ renatagbianchi@gmail.com
}

\author{
Vânia P. A. Neris \\ Departamento de Computação \\ UFSCar \\ São Carlos, SP, Brasil \\ vania@dc.ufscar.br
}

\author{
Anderson L. Ara \\ Departamento de Estatística \\ UFBA \\ Salvador, BA, Brasil \\ alsouzara@gmail.com
}

\begin{abstract}
RESUMO
Designers podem selecionar mídia a partir de tags geradas por usuários em redes sociais, para melhorar seu design com o objetivo de evocar determinadas emoções. No entanto, eles podem confiar nas classificações realizadas? Será que os usuários sentem as mesmas emoções que aquelas associadas à mídia? Este trabalho tem como objetivo auxiliar a tomada de decisão de designers, explorando as emoções de observadores em imagens classificadas por tags. Um estudo empírico online foi realizado com 410 voluntários, que classificaram imagens do Flickr que tinham sido relacionadas pelos usuários da plataforma às cinco emoções básicas e à tag "neutro". Os resultados sugerem que existem diferenças entre tags e emoções sentidas por este grupo de pessoas em emoções específicas. Por outro lado, as descobertas indicam que a seleção de imagens para nojo e raiva precisam de critério adicional.
\end{abstract}

\section{PALAVRAS-CHAVE}

Indexação coletiva, Imagens, Emoções, Design, Estudo empírico

\section{Introdução}

As emoções vêm continuamente chamando a atenção dos pesquisadores. Elas podem ser encontradas em toda interação humana: informação instantânea sobre as situações, elas modelam a tomada de decisão e respostas a estímulos $[4,7]$.

Independente do seu conteúdo, quando elementos de interface de usuário provocam emoções nos observadores, eles são chamados "carregados de emoção" [9].

Mídias sociais é um tema que está em pesquisa com relação ao design com intenção emocional envolvendo principalmente a tomada de decisão de elementos de interface de usuário. No caso das imagens, o designer pode se basear em termos relacionados a emoções escritas em tags por usuários. Em vista disso, o objetivo principal deste artigo é analisar se os designers deveriam selecionar

\footnotetext{
Permission to reproduce or distribute, in whole or in part, material extracted from this work, verbatim, adapted or remixed, as well as the creation or production from the content of such work, is granted without fee for non-commercial use, provided that the original work is properly credited.
}

IHC 2019 - TRILHA ARTIGOS INTERNACIONAIS, Outubro 21-25, 2019, Vitória, Brasil. In Anais Estendidos do XVIII Simpósio Brasileiro sobre Fatores Humanos em Sistemas Computacionais. Porto Alegre: SBC.

(C) 2019 by the author(s), in accordance with the terms of the Creative Common Attribution-NonCommercial 4.0 International Public License (CC BY-NC 4.0). imagens a partir de tags geradas por usuários, e fazer recomendações.

Independentemente de os indexadores terem sentido ou não as emoções, entende-se que de alguma forma decidiram relacioná-las às imagens, o que pode ser utilizado pelos designers com o propósito de evocar emoções. Neste caso, eles devem confiar nas emoções indexadas? Os usuários sentirão as mesmas emoções que foram associadas àquela mídia?

\section{Considerações teóricas}

Existem algumas abordagens para as emoções, dentre as quais a categórica (ou discreta) [8] foi a utilizada nesta pesquisa. Esta classificação fornece uma visão aprofundada de uma lista de emoções básicas, quando comparada a outras abordagens. Além disso, ela inclui cenários para a avaliação que estão integrados com o desenvolvimento geral do eu.

A proposta assume cinco emoções básicas relacionadas a uma combinação de objetivos e planos: i) felicidade - bem sucedido; ii) tristeza - falha ou perda; iii) raiva - frustação; iv) medo - ameaça; v) nojo - repulsão [8].

Indexação coletiva é uma forma alternativa de fazer a indexação de imagens e torna-las acessível, e é também chamada como tagueamento social ou indexação cooperativa [6]. Hastings et al. [5] afirma que "os indivíduos não são apenas usuários mas também criadores e indexadores de informações multimídia”.

\section{Métodos}

\subsection{Participantes}

Uma pesquisa online foi realizada, a qual 410 pessoas completaram e submeteram o formulário. A amostra do estudo inclui apenas aquelas que completaram a pesquisa. No final, os respondentes foram 215 mulheres e 195 homens, com uma idade média de 28.2 - variando de 14 a 86 anos e com mediana de 25 anos. A variância da idade dos participantes foi aproximadamente 113. A pesquisa foi realizada em Português e, por isso, os respondentes eram majoritariamente brasileiros.

\subsection{Estímulo}


Além da adoção das cinco emoções básicas, também foi incluído o estado neutro, que neste estudo foi considerado a ausência das emoções básicas - não sendo assumido como ausência de emoções. Cada emoção citada foi buscada no Flickr [2], um website de compartilhamento de imagens, assim como a tag "neutro", claramente escrita pelos usuários.

Uma seleção manual foi realizada para reduzir o risco de tags incluídas como uma piada e para garantir que uma ampla variedade de contextos de uma mesma emoção fosse apresentada para os participantes (e.g., natureza, pessoas, animais, objetos). Foram selecionadas cinco imagens de cada emoção e do estado neutro, totalizando 30 imagens. Cada uma foi apresentada seguida de cinco barras - uma para cada emoção, variando de 1 a 10, como mostrado na Figura 1.

\section{Análise e resultados}

Algumas imagens resultaram em mais de uma emoção sentida. Todas as imagens de felicidade alcançaram esta emoção como sentida. Apenas uma em cinco imagens foi relacionada a raiva. Dentre as imagens para tristeza, três foram associadas a esta emoção, enquanto uma resultou tanto em felicidade quanto em tristeza e outra apenas em felicidade. As imagens indexadas com a emoção nojo teve o seguinte resultado: duas nojo, uma felicidade e nojo, uma felicidade, e outra tristeza. Todas as imagens indexadas como medo coincidiram, tendo uma delas sido combinada também com tristeza.
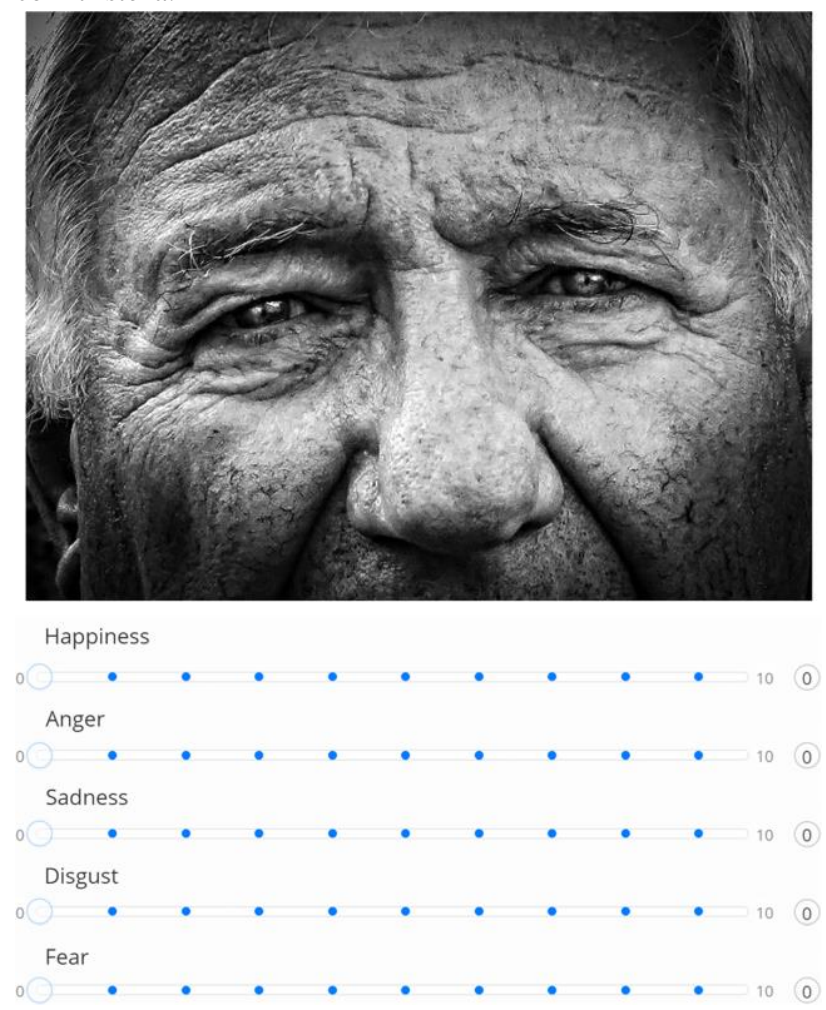

Figura 1: Imagem selecionada do Flickr (indexada como tristeza) e barras para as emoções

\section{CONCLUSÕES}

A análise estatística revelou que as pessoas tendem a claramente distinguir felicidade e medo. Em outras palavras, os participantes sentiram estas emoções quando observaram imagens indexadas com tags correspondentes. A maioria das imagens de tristeza resultou nesta emoção. Por outro lado, pode ser necessário utilizar outros critérios para a seleção de imagens de nojo e raiva. A primeira foi sentida apenas em duas imagens com a tag correspondente. Ainda, apenas uma imagem atingiu raiva, confirmando a literatura com relação à dificuldade de evocar esta emoção usando imagens ao invés de eventos sociais [3]. As recomendações resumidas são apresentadas na Figura 2.

\begin{tabular}{|c|c|}
\hline & Design \\
\hline Felicidade & \\
\hline Tristeza & \\
\hline Medo & \\
\hline Nojo & $\mathbf{X}$ \\
\hline Raiva & $\mathbf{X}$ \\
\hline
\end{tabular}

Figura 2: Recomendações do uso de tags com emoções para o Design

Um exemplo de design que leva à felicidade pode ser visto em sites de entretenimento, como, por exemplo, de turismo [1].

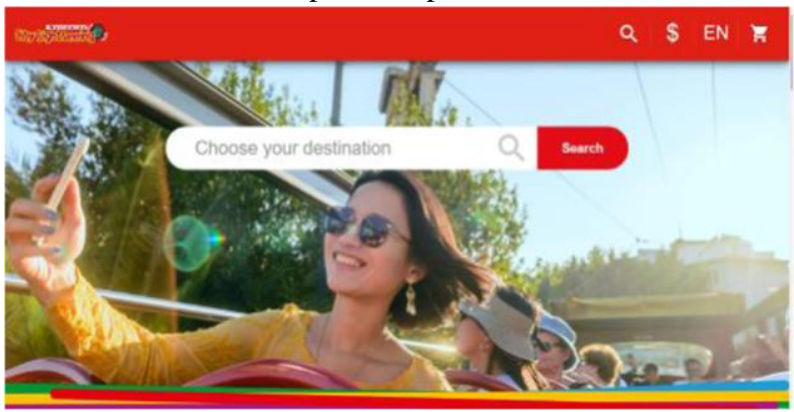

Figura 3: Website de uma agência de turismo [1]

\section{REFERÊNCIAS}

[1] City Sightseeing. https://city-sightseeing.com/en/home (2019). Acessado em: agosto de 2019

[2] Flickr. https://www.flickr.com/ (2019). Acessado em: agosto de 2019

[3] Harmon-Jones E, Amodio DM, Zinner LR (2007) Social psychological methods of emotion elicitation. Handbook of emotion elicitation and assessment, p.91

[4] Harper ER, Rodden T, Rogers Y, Sellen A, Human B (2008) Human-Computer Interaction in the year 2020

[5] Hastings SK, Iyer H, Neal D, Rorissa A, Yoon J (2007) Social computing, folksonomies, and image tagging: Reports from the research front. In: Proceedings of the American Society for Information Science and Technology, 44 , pp. $1-4$

[6] Jörgensen C (2007) Image access, the semantic gap, and social tagging as a paradigm shift

[7] Norman DA (2004) Emotional design: Why we love (or hate) everyday things. Basic books

[8] Power M, Dalgleish T (2008) Cognition and emotion: From order to disorder. Psychology press

[9] Schmidt S, Stock WG (2009) Collective indexing of emotions in images. A study in emotional information retrieval. J Am Soc Inf Sci Technol 60:863-876 